\title{
Assessing Students' Speaking Skill in Online EFL Speaking Course Through Students' Self-made YouTube videos
}

\author{
Syifa Safira Shofatunnisa*, Didi Sukyadi, Pupung Purnawarman
}

\author{
School of Postgraduate Study, Universitas Pendidikan Indonesia, Bandung \\ *Corresponding author. Email: syifa.safira@upi.edu
}

\begin{abstract}
In online EFL speaking course, the teaching and learning activity in the classroom held through the Web 2.0 technologies. Since COVID-19 was announced as national pandemic, all the teaching and learning activities need to be held through online platforms. This also includes the task given to the students, and the assessment done by the teachers. Teachers need to assess students' speaking skill through online platform, namely YouTube. Students uploaded their self-recorded video (SRV) to YouTube, then the teacher assess their speaking skill through the video. In this research, two video samples were purposively selected to be observed using The Public Speaking Competence Rubric (PSCR) by three teachers as the participants, individually. The goal of this study is to discover and compare the results of the assessment from the three participants, and to explore their experience during the assessment process. From this study, it is apparent that although editing is allowed and the speech is partly scripted, students' speaking skill can still be assessed from their speaking manners. The score given by three participants were different from one to another. The PSCR rubric was helpful and considered appropriate to be used in EFL context. However, the basic items needed to assess students' speaking skill is missing in this rubric since this rubric was developed for the native speakers.
\end{abstract}

Keywords: EFL speaking, online assessment, speaking assessment

\section{INTRODUCTION}

Speaking skill as one of the four language skills is the skill that must be drilled simultaneously and assessed accurately using a valid rubric. As higher education students prepare themselves to become the member of global community, they need to prepare their speaking skills to be capable of communicating with the individuals around the world. In order to meet the expected standard of English-speaking skill in higher education in EFL context, a university in Bandung shifted the language learning into the EFL speaking course for the students to practice their speaking skills for communication.

Communication happens between human if there is a linear process between sender and receiver (Shannon, 2001). The aim in the EFL speaking course is to help the students to be more competent in using English for communication both in discussion and public speaking. Thus, the students need to be taught how to send and receive information through communication.
As the technology developed rapidly, communication does not happen only in real-life situation. Students and teacher in Indonesia have been applying the technology in their daily life for communication purposes as well educational purposes (Husnawadi \& Sugianto, 2018; Mahardika, 2019). Since they are familiar with the technology, the Web 2.0 technologies which has various features such as creating content, commenting and collaborating may support the EFL teaching and learning process (Alberth, 2019; Rahmanita \& Cahyono, 2018). This includes the learning process and the assessment.

In adapting technology to the teaching and learning process, the chosen technology should be easy to use and familiar both for the students and teacher. The familiarity between the students or teacher as a user with the technology interface may help them to be capable of interacting using the technology according to Davies and Hewer (2012) as cited in Elhadi (2018). YouTube is a video-based platform that allows the user 
to upload self-made videos content, which also popular among students and teachers in Indonesia (Anugerah, Yuliana, \& Riyanti, 2019; Arigusman, Purnawarman, \& Suherdi, 2018; Dewi, Lengkanawati, \& Purnawarman, 2019).

Video-based learning in blended learning is considered as effective for speaking course, according to Shih (2010). In the research mentioned, the students are asked to create a self-made video in several stages of learning. The self-made video becomes the platform for students to practice and learn throughout the speaking course, which helps them in improving their professional public speaking skills such as enunciation, articulation, facial expression, posture, and gestures. Meanwhile the benefits from the self-recording video (SRV) are mentioned by Encalada and Sarmiento (2019) as follows: providing opportunities to practice the theories and knowledge they gain in the classroom which leads to vocabulary and pronunciation improvement; allowing improvisation which makes students feeling motivated while preparing the SRVs; encouraging students to speak in English with less fear. This also supports the statement from Mahmoud and Ghallab (2020) who reported that utilizing technology allows students to develop their language skills in general and also specific skills in the language they are learning. Besides, uploading their self-made video to YouTube makes students feel a sense of accomplishment when finishing the task (Sun \& Yang, 2015). Sun and Yang (2015) also reported that the nature of self-made video task allowed EFL students to develop their own learning process and strategies.

Meanwhile for the assessment, there are two types of skill measurement that can be done through using the technology: computer-based assessment and technology-based task assessment. Computer-based assessment are scored automatically by the computer makes it easier, faster, and more efficient (García Laborda, 2007). Meanwhile the technology-based tasks are given by the instructors through internet, collected through online technology, then assessed manually by the instructor. Speaking task can be given through technology-based format, but the results still need to be manually assessed by the instructor, or the instructor ask the students to do the self-assessment.

The online format public speaking course allows the students to access the assignments and course materials via the Web 2.0 technologies, which interests the students since they may attend the class less frequently (Clark \& Jones, 2001). In the research, both types of student groups (online and traditional) were given equal materials and assignments, and the students are asked to do self-assessment with the given rubric. Clark and Jones (2001) reported that students' online speaking course and assessment results is not significantly different than the traditional classroom.
The previous researches also have been measuring students' speaking skills through the online task that given by the teachers, in which the students made the self-recorded video and upload it to YouTube for teachers/instructors to watch (Hamilton, 2010; Koesoemah, 2019). After watching students' selfrecorded video through YouTube, the teacher measure students' speaking skills using the available rubric. Online speaking assessment is considered similar to traditional assessment, since the teachers are using the rubric for assessing such as The Public Speaking Competence Rubric (PSCR) (Joe, Kitchen, Chen, \& Feng, n.d.). The difference is only on the platforms used to communicate, since the speaking activity can be done directly in traditional classroom meanwhile in online courses students need to upload it through the web 2.0 technologies

Previous researchers have conducted researches about utilizing the Web 2.0 technologies in speaking classes to drill students' speaking skills and to give them new experiences in learning (Jafari \& Chalak, 2016; Lara Olivo, Yumi Guacho, Padilla Padilla, \& Padilla Padilla, 2020; Minalla, 2018; Mustafa, 2018). Meanwhile other researches mentioned reports on assessing students' skills using various rubrics (Encalada \& Sarmiento, 2019; Schreiber, Paul, \& Shibley, 2012; Yükselir \& Kömür, 2017). However, research about exploring teachers' experience in assessing students' speaking skills using specified rubric through the self-recorded video uploaded to the Web 2.0 technologies is still limited. This study aims to fill the gap by conducting the research guided by these following questions: What are the results of students' speaking skill assessed using PSCR rubric by the teachers through the self-recorded online videos? And how the teachers assess students' speaking skill through self-recorded online videos using the PSCR rubric?

\section{METHOD}

\subsection{Research Design}

In this research, qualitative method is used as the researcher acted as the instructor who assess students' speaking tasks in the online speaking course. In qualitative research, the researcher tries to explain the experience during conducting the research, to shape the world through their perspectives, and identify the experiences (Merriam, 2009). Thus, researcher try to deliberate teachers' experience of assessing students' self-recording video through YouTube using the specified rubric. 


\subsection{Participants}

In this research, three teachers participated to assess students' speaking skill via self-recorded video. The teachers will be referred as teacher 1 , teacher 2 , and teacher 3 throughout this research. Teacher 1 has five years of experience in teaching English language in various courses, and 2 years in the institution. Teacher 2 has similar experiences, he also has 5 years of experience in teaching English, and 2 years in the institution. Meanwhile teacher 3 has 2 years of experience in teaching English speaking course in the institution, and he has never been teaching in different place. The sample of teachers were chosen purposively to participate in this research.

The participants were asked to assess students' speaking skill displayed by the students in the SRV video uploaded to YouTube. All three participants were using the PCSR rubric to assess students' speaking skill. The PCSR rubric assessment criteria will be explained in the instrumentation subsection below.

\subsection{Data Collection and Analysis}

To gain the data for the research, the researcher asked the participant to assess students' speaking skill using PCSR rubric. The PCSR rubric is intended to be used as an assessment of public speaking competency in adult populations, especially in the higher education level that can be used globally (Joe et al., n.d.) This rubric was selected because the SRV students made was intended to be a public video which can be accessed by many audiences. The rubric has 11 competencies which assess various aspect of students speaking skills:

1. Topic Selection: The speaker selects a topic appropriate to the audience and occasion

2. Introduction: The speaker formulates an introduction that orients audience to topic and speaker

3. Organization: The speaker uses an effective organizational pattern

4. Supporting Materials: The speaker locates, synthesizes and employs compelling supporting materials

5. Conclusion: The speaker develops a conclusion that reinforces the thesis and provides psychological closure
6. Word choice: The speaker demonstrates a careful choice of words

7. Vocal expression: The speaker effectively uses vocal expression and paralanguage to engage the audience

8. Nonverbal behavior: The speaker demonstrates nonverbal behavior that supports the verbal message

9. Adapts to audience: The speaker successfully adapts the presentation to the audience

10. Visual aids: The speaker skillfully makes use of visual aids

11. Effectual persuasion: The speaker constructs an effectual persuasive message with credible evidence and sound reasoning

The competencies 1-9 is considered as core criteria, meanwhile the two others (italicized) are the optional dimension which was added after the criteria was evaluated (Schreiber et al., 2012) Each competency of public speaking performance standard in the PCSR rubric is equipped with five criteria: Advanced, Proficient, Basic, Minimal, and Deficient. Each criteria for the performance standard is available in the Appendix 1. However, in this research, the last performance standard (criteria 11) is removed since it is not suitable with the theme of the video. Thus, the PSCR have been re-validated by the secretary of the institution to be used within the institution.

The participants were given the PCSR rubric to fill out, alongside the students' video link. For each participant, there were two documents given because each video needs to be assessed one by one. The documents were sent through WhatsApp, and the teachers send the filled rubrics using e-mail. Each participant assessed students' speaking skills through SRV using the PSCR rubric individually, with no discussion.

To gain participants view about their experience using the PCSR rubric in assessing students' speaking skill through the SRV, semi-structured interview was conducted. The participants were given the list of the questions in advance, but the interview may have extra questions and flexible flow according to their responses. The interview was conducted using voice note feature in WhatsApp to prevent technical issues such as lagging voice, disconnected device, unrecorded calls, and human error. 
Table 1. Observation Results Comparation

\begin{tabular}{lllllll}
\hline Results & \multicolumn{1}{c}{ SRV 1 } & & & SRV 2 \\
Observation point & P1 & P2 & P3 & P1 & P2 & P3 \\
\hline PS1 & 3 & 3 & 3 & 3 & 3 & 3 \\
PS2 & 3 & 4 & 3 & 3 & 4 & 3 \\
PS3 & 3 & 2 & 3 & 3 & 3 & 3 \\
PS4 & 2 & 2 & 2 & 3 & 2 & 1 \\
PS5 & 3 & 1 & 1 & 3 & 2 & 1 \\
PS6 & 2 & 2 & 2 & 2 & 2 & 2 \\
PS7 & 3 & 1 & 2 & 3 & 3 & 3 \\
PS8 & 3 & 3 & 3 & 3 & 4 & 3 \\
PS9 & 3 & 2 & 3 & 3 & 3 & 0 \\
PS10 & 3 & 3 & 3 & 3 & 1 & $21 / 40$ \\
SUM & $28 / 40$ & $28 / 40$ & $25 / 40$ & $29 / 40$ & $27 / 40$ & \\
\hline
\end{tabular}

\section{FINDINGS AND DISCUSSION}

\subsection{Observation Results Comparation}

Since each participant was asked to observe individually, the results of observation will be different. Thus, the researcher will compare the results of participants' observation of students' speaking skill through SRV online videos. There are two students' SRV observed as named 'SRV 1' and 'SRV 2' on Table 1, the 'Performance Standards' in the PCSR displayed as PS1, PS2, PS3, to PS10, and the identity of the participants showed as 'P1' 'P2' 'P3'. From Table 1, it is apparent that rater's background and experience is affecting the students' score even when they are given the exact same SRV as well as the same rubric (PSCR) to rate the SRV. This is in line with the reports summarized and written by Ginther (2013) which found that different backgrounds and experiences will still affect raters' view in assessing even though the raters trained in the same institution.

The first participant and second participant both have 2 years of experience teaching in the institution while also teaching in other higher education courses. Before teaching in the institution and higher education courses, both participants have been teaching for 3 years in various private courses. These two participants may have faced many types of students with various characteristic and background than participant 3 . Meanwhile the third participant only has 2 years of experience in teaching English in the institution and there is no other courses or institution he has joined before. However, participant 3 also may has faced various types of students since he is the participant with most classes to teach in this current batch in the institution. The similarities between three participants are that the participants have 2 years of experience in teaching English in the institution.

Even though participant 3 said in the interview that the PSCR rubric helps rater to be less subjective because of the detailed criteria, it seems that personal preferences and assumption may also affect the assessment results. For example, the score given by participant 1,2 , and 3 to speaker 2 in PS10 are extremely different from one another. Participant 1 gave 3 scores for 'Proficient', participant 2 gave 1 scores for 'Minimal', and participant 3 gave 0 score for 'Deficient.' In the video made by speaker 2 , speaker 2 was commonly seen using still images instead of video footages.

As seen on Figure 1, the speaker gave basic movement to the still images, but it is only as simple as zooming in or out and panning the picture to the left, right, up, or down. Participant 3 stated that the visual provided by the speaker is not helpful since it did not match what was speaker said. It is apparent that participant 2 and participant 3 preferred if the speaker uses movie footage instead of still image to support the speech. Participant 2 said that if the visual aids were not still images, the video will become more interesting, and the audience may have more experience even from solely watching the video. This shows that even though participant 1 and participant 2 have similarities in teaching experience, they have different views in rating the performance standard. All three teachers have similar years of experience in terms of teaching in the institution, but only participant 2 and 3 has similar opinion about this performance standard.

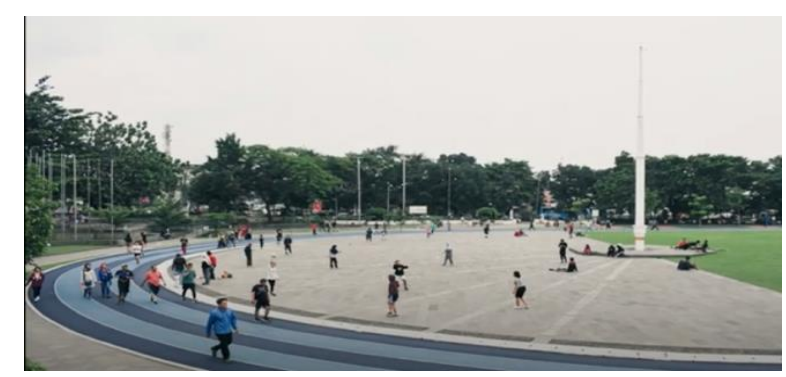

Figure 1 Screenshot from SRV 2

The similar case also apparent in student 1 result in performance standard 5 and 7 which are conclusion and vocal expression. For the conclusion, participant 1 categorized the speaker as 'Proficient', meanwhile both participants 2 and 3 gave her the 'Minimal' criteria. For the vocal expression, participant 1 gave 3 scores for 'Proficient', participant 2 gave 2 scores for 'Basic', meanwhile participant 3 gave 1 score for 'Minimal'. In student 2 results, there are similar cases for performance 
standard 4 and 5 which are supporting materials and conclusion. The score given by the rater is as follows, according to participant order: 3 for 'Proficient', 2 for 'Basic, and ' 1 ' for Minimal.

For the rest of the assessment, we can see that there are not many differences in participants' observation results. However, if we see at the accumulative score, Participant 1 gave the highest score to both SRV among three participants. When questioned about this, the participant acknowledged that she did not give high standards for the speakers. Participant 1 tried to compare the speakers' videos to one another, and she also compared it to her own students' SRV in the same course. This proves that raters' experience is influencing the scores they give for the speaker, even though the specified rubric has been provided for the raters since the participants were not entirely identical in terms of language background or teaching experience, as said by Knoch, Fairbairn, and Huisman (2016).

\subsection{Teachers' Experience in Assessing SRV using PSCR}

After assessing students' speaking skill through the SRV using the PSCR rubrics, the participants were asked about their experience. There are some advantages and disadvantages stated by the participants regarding the experience.

All three participants stated that assessing students' speaking skill from the YouTube videos they made and uploaded is more convenient in term of time. Participant 1 stated that the assessment become simpler in a way that students can display their own speaking ability without having to wait to take turns in class. If speaking skill was assessed in traditional classroom, it takes more time since the time provided was limited and there were too many students to assess. It is hard to organize the students, so they have the chance to speak one by one with the teacher.

Besides, YouTube has appropriate features that allow the teachers to repeat some parts from the video. Participant 2 stated that since the video can be repeated as how audiences want to, it makes the teacher becomes more detailed in assessing small details in the video. If the assessment was done in the traditional classroom and the teacher asks the student to repeat what they say during the assessment process, the students may feel uncomfortable, and the answer may be different. Participant 1 also said similar thing regarding to this matter. She said, even though the students may be reading the text behind the camera, teacher may recognize it through the details in the way they are speaking.

Since the video was allowed to be edited, the participants were asked about their opinion regarding this matter. Participant 1 and 2 agreed that editing may reduce the purity of students' speaking skill. Participant 1 said that the video editing can be a bit confusing, since the visualization of the video may be good but the speech becomes disorganized. Participant 2 said that the background music given by the speaker or the sounds from the footage may reduce the volume of original speaker, which disturbs raters' concentration in assessing. However, the editing may also provide some advantages as stated by participant 1 and participant 3 . Both participants agreed that students may get higher scores since there are many aspects can be scored through the video. Rater may add score for speakers' creativity and content arrangement beside their speaking skills.

When assessing students' speaking skill, all three participants were using the PSCR rubric. All three participants agreed that PSCR helped them in assessing students' speaking skill, and it give them new experiences. Participant 1 said that she discovered that there are many things that can be assessed in students' speaking skill besides their pronunciations and vocabularies. She stated that she never thought of assessing how students open or introduce the topic of the materials before the main points, also the transition between points. Meanwhile participant 2 stated that he often find fillers (such as um.. hm..) in students' speech. However, he never thought it as a criterion of speaking skills until he finds this rubric. He also stated that PSCR helped him to be more detailed in assessing students' speaking skill through the SRV uploaded to YouTube. Meanwhile participant 3 said that the PSCR rubric helped him in a way he was able to recognize the boundary between each criterion, so he can give the score more fairly to the students.

In terms of assessing EFL students speaking skill, the PSCR rubric was considered appropriate by all three participants. Participant 3 stated that this rubric may be more suitable for the students with more exposure of English language rather than the students who has limited exposure to the English language. Participants 2 and 1 said that PSCR is appropriate to use in EFL classroom to assess students' skill since it has the details needed by the raters. However, participant 1 opposed that this assessment rubric lacks in terms of vocabularies, grammar, and pronunciations for EFL students. The performance standard for those items were not detailed, but those items are needed to assess EFL students' speaking skill according to participant 1 . The items mentioned by participant 1 was not detailed in PSCR since this rubric was developed in the nativespeakers institution in the US (Schreiber et al., 2012)

\section{CONCLUSION}

In assessing students' speaking skill through the SRV, the teacher as participants said that the students may benefit from the system since the students were 
allowed to edit the video. However, the teacher also becomes more cautious and detailed in assessing the students' speaking skill through the video. The teacher may repeat the parts of the video to be sure with their judgements of students' speaking skill. In observing detailed students' performance, the teachers said that PSCR rubric was helpful.

The PCSR as assessment rubric used in this research gives new experiences to the teachers as participants. The rubric includes the items that was not being thought by the teachers. However, teachers' various backgrounds and experiences still affect the assessment process, even though the detailed rubric and criteria was given to help them in assessing. This is in line with reports written by Ginther (2013) and Knoch et al. (2016) which stated that teachers' experiences and their language background may influence the assessment process, so the assessment results will be different from one to another.

Besides, the PSCR was considered as appropriate to be used in EFL context since it has detailed rubrics. However, there were some essential and basic items regarding to students' speaking skill is not available in the rubric. It is recommended for future researcher and teachers in online EFL speaking classroom to modify the rubric to make it more suitable to the task, students' condition, and the situation.

\section{REFERENCES}

Alberth. (2019). Use of Facebook, students' intrinsic motivation to study writing, writing self-efficacy and writing performance. Technology, Pedagogy and Education, 28(1), 21-36. https://doi.org/10.1080/1475939X.2018.1552892

Anugerah, R., Yuliana, Y. G. S., \& Riyanti, D. (2019). the Potential of English Learning Videos in Form of Vlog on Youtube for Elt Material Writers. ICoTE Proceedings, 2(2), 224-229. Retrieved from http://jurnal.untan.ac.id/index.php/icote/article/vie w/38232

Arigusman, A., Purnawarman, P., \& Suherdi, D. (2018). EFL Students' Use of Technology in English Lesson in The Digital Era. Indonesian Journal of Curriculum and Educational Technology Studies, 6(2), 77-86. https://doi.org/10.15294/ijcets.v6i2.26599

Clark, R. A., \& Jones, D. (2001). A comparison of traditional and online formats in a public speaking course. Communication Education, 50(2), 109124. https://doi.org/10.1080/03634520109379238

Dewi, F., Lengkanawati, N., \& Purnawarman, P. (2019). Teachers' Consideration in Technology-Integrated Lesson Design-A case of Indonesian EFL
Teachers. International Journal of Emerging Technologies in Learning (IJET), 14(18), 92-107. https://doi.org/https://doi.org/10.3991/ijet.v14i18.9 806

Encalada, M. A. R., \& Sarmiento, S. M. A. (2019). Perceptions about self-recording videos to develop EFL speaking skills in two Ecuadorian universities. Journal of Language Teaching and Research, 10(1), 60-67. https://doi.org/10.17507/jltr.1001.07

García Laborda, J. (2007). Introducing standardized EFL/ESL exams. Language Learning and Technology, 11(2), 3-9.

Ghallab, S. M. Q. (2020). Using Mobile Technology in the Classroom for Teaching Speaking Skill in Yemeni Universities. Language in India, 20(4).

Ginther, A. (2013). Assessment of Speaking. The Encyclopedia of Applied Linguistics. https://doi.org/10.1002/9781405198431.wbeal0882

Hamilton, R. (2010). YouTube for two: online video resources in a student-centered, task-based ESL/EFL environment. Contemporary Issues in Education Research (CIER), 3(8), 27-32.

Husnawadi, H., \& Sugianto, N. (2018). Facebook: An Effective WEB 2.0 Technology for Blended EFL Classrooms in Indonesia. EDULANGUE, 1(1), 6786. https://doi.org/10.20414/edulangue.v1i1.196

Jafari, S., \& Chalak, A. (2016). The role of WhatsApp in teaching vocabulary to Iranian EFL learners at junior high school. English Language Teaching, 9(8), 85-92. https://doi.org/10.5539/elt.v9n8p85

Joe, J., Kitchen, C., Chen, L., \& Feng, G. (n.d.). A prototype public speaking skills assessment: An evaluation of human-scoring quality. ETS Research Report Series, 2015(2), 1-21.

Knoch, U., Fairbairn, J., \& Huisman, A. (2016). An evaluation of an online rater training program for the speaking and writing sub-tests of the Aptis test.

Koesoemah, N. H. (2019). Improving English Spoken Skills through Self Recorded Video for Higher Education Students. JURNAL BAHASA INGGRIS TERAPAN (JOURNAL OF APPLIED ENGLISH), 5(1), 52-65.

Lara Olivo, L. I., Yumi Guacho, L. M., Padilla Padilla, N. M., \& Padilla Padilla, Y. N. (2020). Development of English Speaking skills through the pedagogical use of WhatsApp. Revista ESPACIOS, 41(2).

Mahardika, I. G. N. A. W. (2019). FROM PERSONAL COMPUTER TO FACEBOOK: INFORMATION AND COMMUNICATION TECHNOLOGY AND 
ENGLISH WRITING RESEARCH. Yavana Bhasha: Journal of English Language Education, 2(1), 13-24. https://doi.org/10.25078/yb.v2i1.997

Minalla, A. A. (2018). The Effect of WhatsApp Chat Group in Enhancing EFL Learners' Verbal Interaction outside Classroom Contexts. English Language Teaching, 11(3), 1-7. https://doi.org/10.5539/elt.v11n3p1

Mustafa, E. N. E. (2018). The impact of YouTube, Skype and WhatsApp in improving EFL learners' speaking skill. International Journal of Contemporary Applied Researches, 5(5), 18-31. Retrieved from www.ijcar.net

Rahmanita, M., \& Cahyono, B. Y. (2018). The effect of using Tumblr on the EFL students' ability in writing argumentative essays. Journal of Language Teaching and Research, 9(5), 979-985. https://doi.org/10.17507/jltr.0905.11

Schreiber, L. M., Paul, G. D., \& Shibley, L. R. (2012). The development and test of the public speaking competence rubric. Communication Education, 61(3),

205-233. https://doi.org/10.1080/03634523.2012.670709
Shannon, C. E. (2001). A mathematical theory of communication. ACM SIGMOBILE Mobile Computing and Communications Review, 5(1), 355.

Shih, R. C. (2010). Blended learning using video-based blogs: Public speaking for English as a second language students. Australasian Journal of Educational Technology, 26(6), 883-897. https://doi.org/10.14742/ajet.1048

Sun, Y. C., \& Yang, F. Y. (2015). I help, therefore, I learn: service learning on Web 2.0 in an EFL speaking class. Computer Assisted Language Learning, 28(3), 202-219. https://doi.org/10.1080/09588221.2013.818555

Yükselir, C., \& Kömür, S. (2017). Using Online Videos to Improve Speaking Abilities of EFL Learners. Online Submission, 3(5), 255-266. https://doi.org/10.5281/zenodo.495750 